Article

\title{
Cultural Sets Shape Adult Conceptualizations and Relationships to Nature
}

\author{
Linda Powers Tomasso ${ }^{1,2, * \mathbb{C}}$, Jose Guillermo Cedeño Laurent ${ }^{1}\left(\mathbb{D}\right.$, Jarvis T. Chen ${ }^{2,3}$, Paul J. Catalano ${ }^{4,5}$ \\ and John D. Spengler ${ }^{1}$ \\ 1 Department of Environmental Health, Harvard T.H. Chan School of Public Health, Boston, MA 02115, USA; \\ jcedenol@hsph.harvard.edu (J.G.C.L.); spengler@hsph.harvard.edu (J.D.S.) \\ 2 Population Health Sciences, Harvard University, Boston, MA 02115, USA; jarvis@hsph.harvard.edu \\ 3 Department of Social and Behavioral Sciences, Harvard T.H. Chan School of Public Health, \\ Boston, MA 02115, USA \\ 4 Department of Data Science, Dana-Farber Cancer Institute, Boston, MA 02115, USA; \\ pcata@ds.dfci.harvard.edu \\ 5 Department of Biostatistics, Harvard T.H. Chan School of Public Health, Boston, MA 02115, USA \\ * Correspondence: tomasso@hsph.harvard.edu
}

Citation: Tomasso, L.P.; Cedeño Laurent, J.G.; Chen, J.T.; Catalano, P.J.; Spengler, J.D. Cultural Sets Shape Adult Conceptualizations and Relationships to Nature. Sustainability 2021, 13, 11266. https://doi.org/ $10.3390 /$ su132011266

Academic Editors: Chun-Yen Chang and William C. Sullivan

Received: 23 August 2021

Accepted: 7 October 2021

Published: 13 October 2021

Publisher's Note: MDPI stays neutral with regard to jurisdictional claims in published maps and institutional affiliations.

Copyright: (c) 2021 by the authors. Licensee MDPI, Basel, Switzerland. This article is an open access article distributed under the terms and conditions of the Creative Commons Attribution (CC BY) license (https:/ / creativecommons.org/licenses/by/ $4.0 /)$.

\begin{abstract}
The variability of nature and the nature construct have complicated interpretations of empirical evidence from nature-based health studies. The challenge of defining nature exposure for purposes of methodological standardization may encompass constructs beyond vegetated landcover. This study offers a new construct for defining 'nature exposure' that considers cultural sets and nature familiarity. Focus group discussions across the United States $(\mathrm{N}=126)$ explored the concept of what constitutes the relationship to nature. The participant diversity included regions, cultural demographics, cumulative nature experience, and everyday nature exposure. Mixed methods of semi-structured discussion and a photo exercise that prompted nature connectedness allowed for data triangulation and the detection of contradictions between approaches. Individuals conceptualized nature in ways reflecting highly personal and differentiated experiences, which defied consensus toward a single nature construct. The group scoring of photo imagery showed consistent high and low levels of nature connectedness with respect to wildness and outdoor urban venues, respectively, but diverged in the assessment of nature within the built environment. Everyday nature exposure significantly differentiated how groups conceptualized and related to nature imagery. This result may indicate an unmet biophilic need among groups with low backgrounds of nature exposure. The contrasts between the discussion content and the observed reactions to nature imagery showed the value of using mixed methods in qualitative research.
\end{abstract}

Keywords: nature-health relationships; human-nature experience; urban nature; biophilia; nature exposure; focus group discussions; qualitative; photo research

\section{Introduction \\ 1.1. Background}

The current understanding of associations between nature and health has relied on crude indicators of exposure to nature. Further, the benefits derived from exposure to nature are likely to vary depending on one's innate connectedness to nature, which is nurtured by acquired experiences and stimulated biophilic responses [1]. Many studies on nature and wellbeing have acknowledged the role of personal affinity to nature [2-7]. Fewer considered how limited contact with nature [8-10] or health advisories proscribing outdoor play in polluted environments [11-13] lead to fear of or aversion toward nature. Demographic features of urban landscape contexts also influence wellbeing [14-17], although evidence is growing for how race, ethnicity, socioeconomic status (SES), gender, age, region, and 
urbanicity can modify nature relationships [18-23]. Attention to differences in the sociocultural underpinnings of contact with nature across diverse populations is highly germane to research on health and health disparities. The origins of nature relationships deserve scrutiny, as they combine with familiarity with nature and formative experiences to define a learned cultural set regarding nature. Opportunities to pursue comprehensive, inclusive ethnographic research on nature use by cultural sets are infrequent, however, such that knowledge of the bases, permanence, and plasticity of individual relationships to nature is incomplete [24]. Knowing if and where perceptual differences exist with respect to nature is a preliminary step for investigating why individuals and their identifying groups can vary in their relationships with, responses to, and use of nature-based environments.

\subsection{Literature Review}

Humans have evolved by relying on nature for existential, spiritual, and material fulfillment. Interacting with nature as a tangible rather than abstract premise has not made humans' relationship with nature easier to apprehend. On one hand, natural structures have inspired biomimetic invention in fields as imaginative as poetry, aviation, and architecture. Conversely, immaterial concepts, such as sublimity and awe, are commonly illustrated by natural phenomena, such as sunsets and spider web geometry. Faced with the task of stating what 'nature' is, the Ionians chose only to assign nature a relational meaning, not to define it. Early philosophers identified "nature with some particular and definite thing and thus [gave] it a concrete definition. Thales said it was 'water.' Anaximenes said it was 'air.' Heraclitus said it was 'fire'" [25]. Though the Greeks found it impossible to define the abstraction of nature, they nonetheless agreed on explaining its cosmogenesis and related that account to human wellbeing.

The literature supports the observation that human responses to "nature" are heterogeneous and quite varied. An early range of response evidence was centered on aesthetic preference and emotional experiences in nature rooted in environmental psychology [26-29]. Cultural factors entered research on urban nature responses, particularly for urban forests [30-34], thus strengthening the relevance of cultural preference for urban planning and design. Much has been learned through subsequent comparisons of physical, participatory, and affective responses to nature exposure according to sociodemographic groupings. In addition to race and ethnicity, studies have considered responses to nature according to urban and rural residency [35,36], Latino heritage [37,38], race, age, and residence [39-41], immigrant status [42-44], and disability [45], finding characteristics of these varied cultural settings that shape group-level nature relationships. However, the studies on each group of interest are few.

One of the strongest theoretical explanations for connection to nature is the biophilia hypothesis, which states that individuals have an intrinsic affinity for nature [46,47]. Biophilia sustains the desire for nature connectedness (NC) [48-50] and its close constructs of "nature relatedness"(NR) [51-54] and "nature affinity" [55,56]. These concepts strongly signal individuals' predisposition for comfort in and valuation of nature [57]. Relating to nature contributes to health and wellbeing through anxiety reduction $[58,59]$ and perceived restorativeness, which is linked to the biophilic quality of in situ natural environments [60]. For this study, we chose NC as our construct of interest to aid in the analysis of humannature response patterns. NC emphasizes the cognitive component of nature associations and modes in which built environments impact nature relationships [61], which is consistent with the scoring instrument that this study will employ. Numerous validated scales developed to assess NC or NR $[49,53,62-67]$ have been used in research to predict pro-environmental attitudes and their complementary behaviors [55,68-71] and to support the conclusion that environmental behaviors are strengthened by time in nature [2,72-77], which often has roots in childhood exposure and affinities cultivated during this formative imprinting [78-80].

Cultural sets may lead individuals to view and connect with nature differently. Sociodemographic examinations of NC have highlighted the influence of race [81-83], 
SES [84], and cultural politics [85] in evaluating nature participation. Race-based preference research generally considers urban parks and amenities to understand nature use among Blacks [86,87] and Hispanics [32] vis-a-vis whites, which is a shortcoming given the long trajectory of outdoor landscape use and environmental engagement by Black Americans $[88,89]$. Recent scholarship has shown that race does not differentiate white from non-white attitudes toward non-urban wildness among college students [81], despite exclusionary social attitudes and management protocols in wilderness, which may curtail Black use of those spaces $[82,85,90]$. SES differences impact the availability and quality of nature in urban greenspace in ways that are independent of race [91]. While linked to race, income and educational attainment predict opportunities for outdoor recreation [92,93], and low SES predicts that urban environmental risks deter outdoor play among poorer children [94-96]. Moreover, white attitudes toward nature are not monolithic and are shown to vary by gender [97,98] and age [99].

Viewing photo imagery as a nature exposure proxy follows previous study designs that use nature facsimiles to test their effects [100-102]. Simulating live nature exposure through photos has allowed researchers to test recovery from mental fatigue $[103,104]$, examine psychological restoration [105-107], and measure subjective physical and mental energy in response to scenes of natural and built environments [108]. Photo use has also captured the variability in respondents' perceptions of nature according to immigrant culture [109], nature preference by race/ethnicity [110,111], and correlation between aesthetic judgements and affective responses in appraising nature [112]. Kaplan and Talbot elaborated a threephase photo presentation to discern preferences for built versus natural settings by race and identifiable variables underlying choice [34]. Photos of nature and built environments are methodologically useful as community audit tools [113-115], while participatory photo research has mapped positive emotional responses from encountering nature in everyday surroundings [116] and a "geo-narrative" of nature immersion [117].

The use of pictorial images as a research instrument has been recognized as an effective device for communicating a nuanced understanding for both individual and collective interpretations of nature $[113,118]$. From a pragmatic perspective, substituting imagery for live landscapes can reduce the logistical burdens of exposure comparisons and open to otherwise unattainable sociodemographic participation. Criticism of early environmental research for presenting exaggerated contrasts between natured vs. non-natured settings, e.g., inanimate urban vs. idyllic wilderness settings [102,119,120], or subjective, scenic quality assessments between older, white, mid-high SES respondents and younger, Black, low-SES respondents [114] has yielded more graduated comparisons, e.g., rural-urban settings [121,122]. Research has shown viewing both simulated and live nature to be restorative, though the greater effect was shown by live nature [123], while looking at nature imagery elicited the same psychological and physical effects of an actual nature encounter $[124,125]$.

\subsection{Hypothesis and Reasons for This Study}

We pursue two objectives in this paper. First, we assess how individuals conceptualize nature and how cultural sets, which include nature familiarity, influence those appraisals. Second, we analyze how self-perceived NC influences biophilic interpretations of nature imagery in an effort to uncover any prototypical group-level similarities and distinctions among study participants that characterize nature relationships. We use nature imagery to test the hypothesis that varying background levels of nature will lead individuals to define and regard nature differentially according to their cultural sets, nature expectations, and urbanicity gradients-distinct interactions that may hold implications for human biophilic responses to contact with nature. 


\section{Materials and Study Design}

\subsection{Study Design and Methodology}

This study combined qualitative and quantitative research methods [126-130]. Parallel mixed methods were used to examine instances of convergence and divergence between two data sources to examine individuals' interactions with conceptually and pictorially expressed nature [131,132]. We compared coded qualitative data from semi-structured focus group discussions against quantitative data derived from NC scoring in the photo exercise to satisfy this approach. Mixed methods have been used in studies of nature, built environments, and health [101,133], though few public health studies were identified that utilized focus group discussion content supported by photo prompts to elicit participants' opinions [134-136], as done here.

\subsection{Study Recruitment}

A two-stage recruitment process took place through Facebook advertisements placed in four U.S. metropolitan areas. The inclusion criteria included an adult age of $18+$ and residence in one of the targeted metropolitan areas. A total of 596 participants registered through the online portal where they listed only city and gender, resulting in a metapopulation of $82.8 \%$ women, $15.0 \%$ men, and $1.5 \%$ gender non-conforming. All enrollees who identified as male or non-binary received emailed invitations to attend a focus group; females were invited chronologically until twelve participants per group confirmed attendance. Expanded recruitment through academic and community partnerships led to additional focus groups being held in targeted cities to generate a final study population $(\mathrm{N}=126)$. Seventy-five individuals enrolled through Harvard Qualtrics (Facebook, Georgia State, Arizona State Universities), and 51 enrolled through outside organizational contacts (government conservation officials, land trust members, a community youth mentorship group, Latin American childcare givers). All final study participants voluntarily enrolled and provided electronic consent. Table S1 (Supplementary Materials) describes the focus group characteristics.

\subsection{Study Sites}

We convened participants in the environs of San Francisco, Atlanta, Phoenix, Boston, and Hartford for sessions at a community meeting room or university classroom. Exceptions were the session organized for conservation officers at their annual national conference and a final discussion over Zoom in accordance with IRB protocol restrictions due to COVID-19. Figure S1 illustrates the focus group locations.

\subsection{Participatory Research Tools}

The focus group sessions lasted $1.45 \mathrm{~h}$ and were divided into a one-hour semistructured discussion and a 45-min group exercise in order to examine conventional nature-based scenes for the evocation of NC. The discussions conformed to a topic guide (Table S2) to solicit individual attitudes toward nature and were developed from background literature [137-140] and recommendations for further nature-health inquiries [24]. Two approximately equally sized subgroups were formed for the photo exercise; where possible, previously acquainted participants were separated to minimize correlated results. To operationalize the nature construct, the research team selected thirty-four photos with varying compositions of nature, human, and constructed objects for their potential to stimulate cross-cutting and interactive discussion based on universal scene familiarity and content objectivity [135]. Pictorial images ranged from biophilic elements within built environments to settings for outdoor activities and full nature landscapes (Figures 1 and S2). The exploration of the settings where most individuals might interact with nature gave license for our diverse participant base to describe any positive and negative affects experienced while viewing these scenes and to justify their intuitive feelings and concerns arising from the features depicted [118]. Each subgroup evaluated all 34 photos for the NC perceptions. 

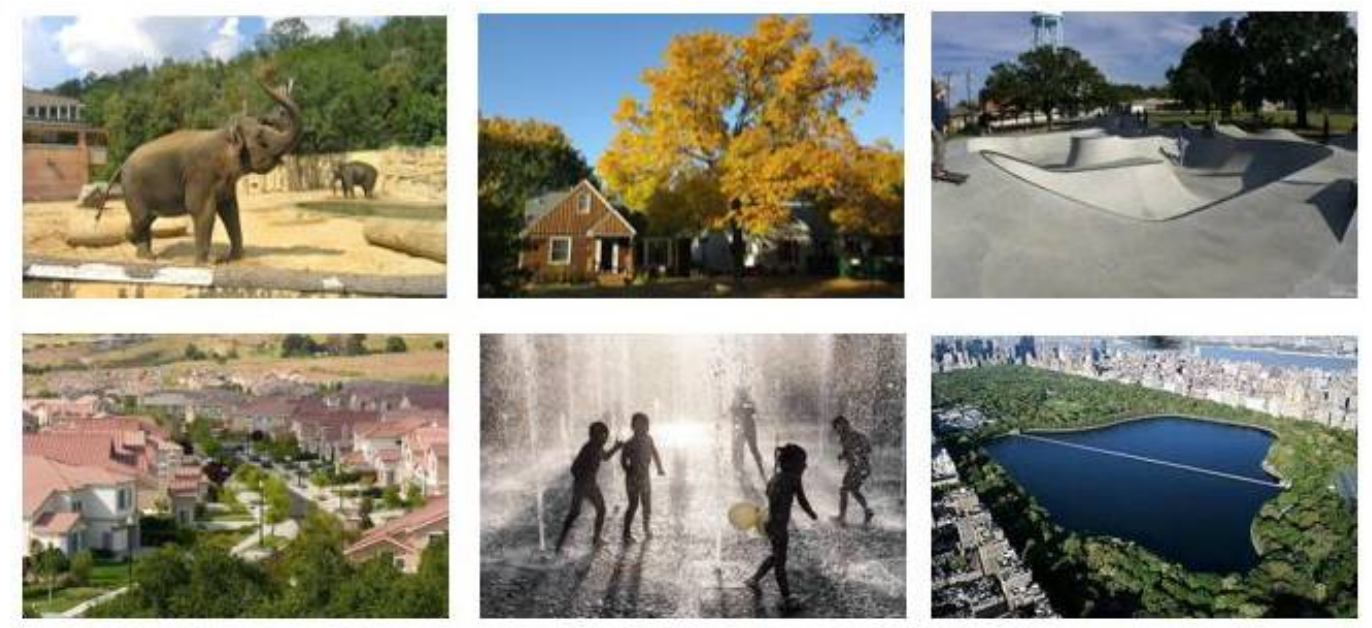

Figure 1. Sample photo images representing nature-based scenes to rate NC. The full photo array is shown in Figure S2.

NC was self-assessed through the Inclusion of Nature in the Self (INS) scale, a validated, one-item psychometric tool [61]. The INS scale features seven degrees of NC that are indicated by overlapping Venn diagrams, where 1 represents exclusion of nature from the self and 7 represents oneness with nature (Figure 2). Participants were instructed to deliberate within their subgroups on the question "How connected to nature does this image make you feel?" as elicited prima facie by each photo and to explain their personal responses. The scoring resulted from a consensus process arrived at through group discussion and captured rationale for NC that would have been lost through silent scoring by individuals. The group deliberation around $\mathrm{NC}$ thus generated additional qualitative data that supplemented the semi-structured discussion around nature contact. One consensusderived INS score was recorded on the paper strip shown in Figure 2 and affixed to each image. Outlier scores were also recorded if they fell two or more INS levels from the group consensus and were weighted in the final analysis. The researcher remained silent during photo discussions to allow the participants to freely interpret visual content without the interjection of language cues or researcher bias. The photo exercise produced 646 discrete NC scores for the photo set across the ten groups.

\begin{tabular}{|ccccccc}
\hline \multicolumn{7}{c|}{ Answer options } \\
\hline 1 & 2 & 3 & 4 & 5 & 6 & 7 \\
\hline Self Nature & Self Nature & Self Nature & Self Nature & Self Nature & Self Nature & Self Nature \\
0 & 0 & 0 & 0 & 0 & 0 & 0 \\
\hline
\end{tabular}

Figure 2. Inclusion of Nature in the Self scale (Schultz, 2002), a single-item scale measuring NC.

\subsection{Data Collection}

Data were collected during in-person focus group sessions held between September 2019 and January 2020 and over Zoom in November 2020. The interviews were digitally recorded with participants' permission and transcribed verbatim to ensure accuracy. The transcripts contained no identifiable participant information. The subgroup photo discussions were audio-recorded simultaneously on two separate devices with the participants' consent. Theoretical data saturation was determined when no new themes arose through on-going data analysis or the addition of diverse groups such that adequate sampling representation had been achieved [141]. Participants received a small retail gift card at the end of the session to acknowledge their time. 


\subsection{Data Analysis}

Data analysis methods are briefly described here but are fully presented in Tomasso et al. [142]. Transcribed discussion content was analyzed and managed through a process of inductive thematic coding using the NVivo 12 Plus software [143]. Qualitative analysis of 163 transcript pages yielded 789 coded elements, 66 substantive themes, 15 organizational themes, and 3 synthesized final themes. After the initial transcript review, the first analyst identified codes based on prior subject knowledge and interfacing with the focus groups. She subsequently developed a code manual to define subthemes-specifying when and when not to use each [144] — to share with the second analyst. Each analyst independently coded the transcripts, with the second analyst identifying additional subthemes that produced a final codebook. Internal analytical validity was strengthened through the analysts' regular discussions of contextual meaning through increasing familiarity with the transcripts' contents and participants' intentions, and open coding ascribed additional subthemes to the initial organizational scheme when omissions and new ideas were detected [130]. Inter-rater reliability was maintained through multiple and separate readings of transcripts to reconcile coding discrepancies; overlapping subthemes were merged and some nascent themes were dropped when the text evidence proved insufficient [145]. The two analysts reached concordance on $82.6 \%$ of the separately coded transcript content $[127,146]$. An unweighted kappa coefficient of $78.3 \%$ measured the analyst agreement and was corrected for chance.

The quotes in Tables 2-4 represent thematic data extracted from the coded transcripts and exemplify their respective organizational themes, e.g., defining nature, experiencing nature, and nature vis-à-vis the outdoors. INS scores from the photo exercise were categorized according to group-level nature exposure. INS scores from the photo exercise were categorized according to group-level nature exposure as determined by the density of surrounding built and natural environments of the focus group areas and participants comments. Categorical means for each nature scene were analyzed and visualized as ggplot2 boxplots. The normality of the data distribution was examined by means of the Shapiro-Wilk test, and the data were found to be non-normally distributed ( $\mathrm{W}=0.92$, $\left.p<2.2 \times 10^{-16}\right)$. Kruskal-Wallis rank sum tests were used to show significance in the differences in the mean INS scores among the three categories and as pair-wise group tests.

All statistical analyses were performed in R version 3.6.3. The Harvard T.H. Chan School of Public Health Institutional Review Board determined the study to be exempt under IRB reference number 19-1419 on 28 August 2019. Arizona and Georgia State Universities additionally consented to allow data collection under the referenced IRB.

\section{Results}

\subsection{Focus Group Discussion}

The first part of the focus group-where a set of participants that was diverse in terms of age, gender, geographic location, socioeconomic status, and race freely discussed their nature relationships - exposed a range of views based on cultural sets and nature familiarity. Still, three homogeneous populations emerged around levels of nature encountered in everyday living and working environments, which may have influenced perceived nature connectivity. We categorized the levels of nature exposure according to the participants ${ }^{\prime}$ comments about the frequency and opportunity of accessing nature and the density of the built environment of the focus group location (Table 1), hypothesizing that everyday exposure would condition biophilic inclinations toward nature, as depicted in the photos. We subsequently observed through the scoring consensus process that group-level nature exposure indeed shaped enthusiasms and degrees of connectedness toward the various nature images, and that categorization by everyday nature exposure translated into distinguishable NC patterns by group type. 
Table 1. Categorization of focus groups according to the level of everyday nature exposure.

\begin{tabular}{|c|c|c|c|c|c|}
\hline $\begin{array}{l}\text { Nature } \\
\text { Exposure }\end{array}$ & $\begin{array}{l}\text { Focus Group } \\
\text { Site }\end{array}$ & $\begin{array}{l}\text { Group } \\
\text { Characteristic }\end{array}$ & $\begin{array}{l}\text { Age } \\
\text { Range }\end{array}$ & $\mathbf{N}=$ & Comment \\
\hline High & Rural WV & $\begin{array}{l}\text { Government } \\
\text { conservation } \\
\text { agents }\end{array}$ & $40-65$ & 15 & $\begin{array}{l}\text { I was able to get a seasonal conservation law enforcement } \\
\text { position with the state. And it was my first introduction } \\
\text { to the environment. And I'm like, wait a minute, just like } \\
\text { so many guys-click-I can bring both these passions } \\
\text { together and this is my future. }\end{array}$ \\
\hline High & Suburban CT & $\begin{array}{l}\text { Land trust } \\
\text { members }\end{array}$ & $50+$ & 19 & $\begin{array}{l}\text { I'm definitely one of those introverts who likes to go into } \\
\text { nature to renew and get away from people. So if it's nice } \\
\text { weekend weather, I may not go because I know that I am } \\
\text { not going to get that nice peaceful feeling that I would } \\
\text { like. So having an area that's not overly populated is } \\
\text { really helpful. }\end{array}$ \\
\hline High & Tempe, AZ & Graduate Students & $25-35$ & 11 & $\begin{array}{l}\text { I never consider any sort of city or like urban, I almost } \\
\text { never consider anything like that to be nature because it's } \\
\text { all been sculpted. Even if there are trees and stuff around, } \\
\text { they've almost certainly been planted there by human } \\
\text { hands and the soil that's there is not a native soil for that } \\
\text { type of plant species. }\end{array}$ \\
\hline Medium & $\begin{array}{l}\text { Suburban } \\
\text { Atlanta }\end{array}$ & $\begin{array}{l}\text { Facebook ad } \\
\text { respondents }\end{array}$ & $25-80$ & 11 & $\begin{array}{l}\text { So I guess it would be-for me to really feel like I'm in } \\
\text { nature-I would not want sounds of the } \\
\text { man-made environment. }\end{array}$ \\
\hline Medium & Berkeley, CA & $\begin{array}{l}\text { Facebook ad } \\
\text { respondents }\end{array}$ & $25-70$ & 13 & $\begin{array}{l}\text { Right now where I go for nature is the Bay's regional } \\
\text { park. Amazing they're so close. It was the city right up to } \\
\text { the edge and then forever green. Built-up since we moved } \\
\text { here. But there's still park forever. I think I really am } \\
\text { drawn to urban living and wilderness longing. }\end{array}$ \\
\hline Medium & Boston, MA & $\begin{array}{l}\text { Facebook ad } \\
\text { respondents }\end{array}$ & $25-75$ & & $\begin{array}{l}\text { I feel like my definition of nature has changed depending } \\
\text { on where I am. Out west, I would not consider an } \\
\text { arboretum an example of nature but in Boston I would. It } \\
\text { also depends on the density of the population. So inside a } \\
\text { city where there's so many people, I would consider a } \\
\text { patch of green free of noises and stuff to be part of nature. }\end{array}$ \\
\hline Medium & $\begin{array}{l}\text { Suburban } \\
\text { Phoenix }\end{array}$ & $\begin{array}{l}\text { Facebook ad } \\
\text { respondents }\end{array}$ & $40-70$ & 10 & $\begin{array}{l}\text { The takeaway is that the more familiar you are with the } \\
\text { processes of nature, the more restricted it is how you } \\
\text { define it, with the definition, with its limits. The more } \\
\text { restricted maybe it is how, what you define it as where it } \\
\text { limits or changes. }\end{array}$ \\
\hline Low & Urban CT & $\begin{array}{l}\text { Community youth } \\
\text { mentorship } \\
\text { program }\end{array}$ & $18-22$ & 10 & $\begin{array}{l}\text { I've been to other areas, like I was thinking of Louisville, } \\
\text { Kentucky which is nice, because I guess I don't like a more } \\
\text { rural area, I do like a mixture of I guess more } \\
\text { suburbanish, if not urban. But the feeling of being in a } \\
\text { place where you're like, ok-it's modern but there's still a } \\
\text { sense of, you know, trees. }\end{array}$ \\
\hline Low & $\begin{array}{l}\text { Downtown } \\
\text { Atlanta }\end{array}$ & $\begin{array}{l}\text { Undergraduate } \\
\text { students }\end{array}$ & $18-22$ & 15 & $\begin{array}{l}\text { I feel like I want to go to a mountain or something more } \\
\text { scenic, which is where nature is to me, I have to get in my } \\
\text { car and drive at least two hours. So I feel like this city is } \\
\text { helping me redefine what nature touchpoints may be and } \\
\text { bringing those to me but I don't know if it's making it } \\
\text { more effortless. }\end{array}$ \\
\hline Low & $\begin{array}{l}\text { Sacramento, } \\
\text { CA }\end{array}$ & $\begin{array}{l}\text { Latin American } \\
\text { childcare workers }\end{array}$ & $24-28$ & 8 & $\begin{array}{l}\text { Today, technology means there is no time to even take a } \\
10 \text { - minute walk outside. So everyone gets lazy and } \\
\text { reaches for the easiest, most accessible thing there is to do } \\
\text { rather than any effort to go outside. When someone is in a } \\
\text { new place, or a foreign country, what you want to do } \\
\text { most is to explore. I don't have a car, but I take the kids' } \\
\text { stroller and take them to explore. }\end{array}$ \\
\hline
\end{tabular}


Discussions showed that the cultural set and nature familiarity influenced response patterns in how individuals related to nature. Thematic analysis of the discussion transcripts revealed that participants had such divergent experiential reference points in nature that formed their own nature relationships that they prevented agreement on a shared nature construct. The comments in Table 2 reflect the subjectivity and diversity of nature experiences that participants felt had precluded agreement on a common nature construct within their respective groups. This disagreement speaks to the multiple meanings that participants attributed to individual nature experiences given the background nature familiarity, affinity, and opportunities in nature that they brought to the discussion.

Table 2. The participants' comments reflect non-consensual views of a nature construct.

- I think nature is so insanely subjective from person to person that it really depends on your definition of nature. Because, for example, I think we all have an idea of a national park being, "nature," but what else counts? Female, mid-40s, Berkeley

- At least define what nature is, because there's 20 different definitions of nature right here, right? Male, late 40s, conservationist

- So everybody's nature thing is different, everybody's definition of it is different. I don't know, we do need to change [that perspective]. Female, 18 y/o, Urban CT

- My takeaway is that the more familiar you are with the processes of nature, the more restricted your definition is-its limits, its changes. Female, early 50s, Berkeley

- I think there's always gonna be this spectrum of what nature is, whether it's our own little garden that we plant, or that which is the other extreme of being out in the wilderness. Female, late 30s, Atlanta

Disagreement about the role and importance that individuals attributed to nature between focus groups was less pronounced within the focus groups. The cultural set, urbanicity, and level of everyday nature exposure distinctly influenced individuals' positions toward nature. Individuals with lower nature exposure described their nature interactions more ecumenically, with repeated references to stars and the sky, weather, and insects. More nature-immersed individuals instead selectively qualified nature drawn from a variety of landscape-scale experiences. This divergence resulted in an imbalanced construct of nature based on lived experience, where those with less prior nature exposure tended toward a more expansive view, while those more highly immersed in nature favored the landscape scale and intensity of experiences while eliminating urban spaces from their definition of nature (Table 3).

Table 3. Experience in nature conditions acceptability for what is and is not nature.

- I realize now how important one's experience in nature is in different places at different times and different points in life. Male, mid-60s, Phoenix.

- Nature is very subjective due to your own individual experiences. It's seems like what you agreed on was that my personal prejudices made me hesitant about connecting. It's not lifestyle, it's experiential. How you react to the experiences. Female, late 20s, Berkeley

- $\quad F o r$ me, it would depend if, for example, that little dandelion in the sidewalk, if I really wanted to study that and find the nature that I would, then I can, my instant gratification is no. Male, mid-50s, conservationist

- Flipside is, though, if I'm in a really urban environment, I gravitate to whatever looks like life. So that little dandelion in something that's really nature. I'm not probably paying much attention to it, but if all I see is concrete, it looks pretty damn good. Female, mid-40s, conservationist

Most individuals, irrespective of the group, disagreed with the idea that the outdoors and nature represent the same concept. In certain situations, the outdoors offered some consistent emotional benefits of time in nature, particularly when the outdoors was a familiar extension of one's home, such as an outdoor patio or backyard garden. Urban individuals were more likely to reference the outdoors in terms of infrastructure, transit dependency, and schedules-factors that impede a sense of retreat that is available in 
purely nature-centered environments. A few participants described their desire to escape into nature even during moments outdoors (Table 4).

Table 4. Outdoors and nature are not the same concept for most individuals.

- I don't think outdoors and being in nature are the same thing. I feel like there's a difference. Because when I walk to my bus in the morning, I'm outside but I don't really feel around nature. Because it's mostly me walking by buildings, houses, I go across the bridge, I look over the side and I see a freeway. And I get on the bus and there's not really nature around me. But then when I worked at a summer camp there was nature everywhere. There was trees as long as I could see, there was hiking trails, there was a nice river. There's a big difference between both. Male, college-age, urban CT

- I could be outdoors and not feel like I'm in nature. I have dogs, I have to take them outside twice a day, I'm always outside. But I would have to actually be more aware to feel like I'm in nature. So sometimes I'll look around because there's a wooded area by my apartment or I'll notice fireflies at night. That makes me feel like I'm in nature but just being outdoors for me doesn't feel like I'm in nature, it just feels like outside. Female, college age, Urban Atlanta

- Outdoors is a soccer field. Nature is Mt. Ranier. Male, early 50s, conservationist

- It's like a continuum. Outdoors. You're outside. It has some nature. Bugs or dog, whatever. But I don't think of being in the middle of Phoenix as being in nature. You know, I want to go out even if I'm outdoors. Yeah, I'm outside where there's not manmade structures or rivers. And the further away from people and people-things is more nature. Male, early 60s, Phoenix

\subsection{Photo Exercise for Rating Nature Connectedness}

The results of the photo exercise gave a more nuanced interpretation of how groups related to nature than the discussion comments alone. The photos allowed the focus groups to operationalize the construct of NC by using the INS scale across a range of familiar nature scenes. The mean INS scores for each photo image were grouped categorically by everyday nature exposure categories: Peak-level nature exposure characterized conservation wardens, land conservationists, and Western-based graduate students (blue, $\mathrm{N}=204$ ); medium-level exposure characterized the Facebook ad respondents in Boston, Berkeley, suburban Atlanta, and Phoenix (green, $\mathrm{N}=272$ ); low-level exposure characterized the participants in urban Atlanta and urban Connecticut and the Latin American childcare workers in Sacramento (red, $\mathrm{N}=170$ ). The results are depicted in Figure 3.

Despite the great diversity in lifetime nature engagement within the focus groups, general agreement was observed between categorical levels of everyday nature exposure and INS scores to signal what does and does not constitute nature. All three groups registered low mean scores for scenes that did not inspire NC and similarly high means for scenes that were indisputably natured. However, for images depicting nature found within the built environment, the INS scores trended higher among groups from nature-deprived areas and lower among groups who were more accustomed to abundant nature. Groups with medium-level nature exposure often arrived at higher mean NC scores and larger scoring ranges than either the peak- or low-exposure groups.

We had initially hypothesized that individuals with lower standard nature exposure would define nature more liberally, especially nature encountered in settings in built environments. The outcomes of the photo exercise generally met this hypothesis. However, we observed that individuals shed their personal-experience-based definitions of nature in entering the shared emotional terrain of NC for the photo exercise. The overall scoring of the nature images for perceived NC produced surprisingly steady patterns across the categories of group-level nature exposure. The NC scores converged at both the high and low extremes of the seven-point INS scale, indicating groups' agreement on nature contexts that did and did not elicit nature affinity. Images of wild nature uniformly received high INS scores, while the low scores that were assigned to scenes of outdoor recreational facilities, including an urban greenway, expressed generalized disconnection from nature (Figure 4). 


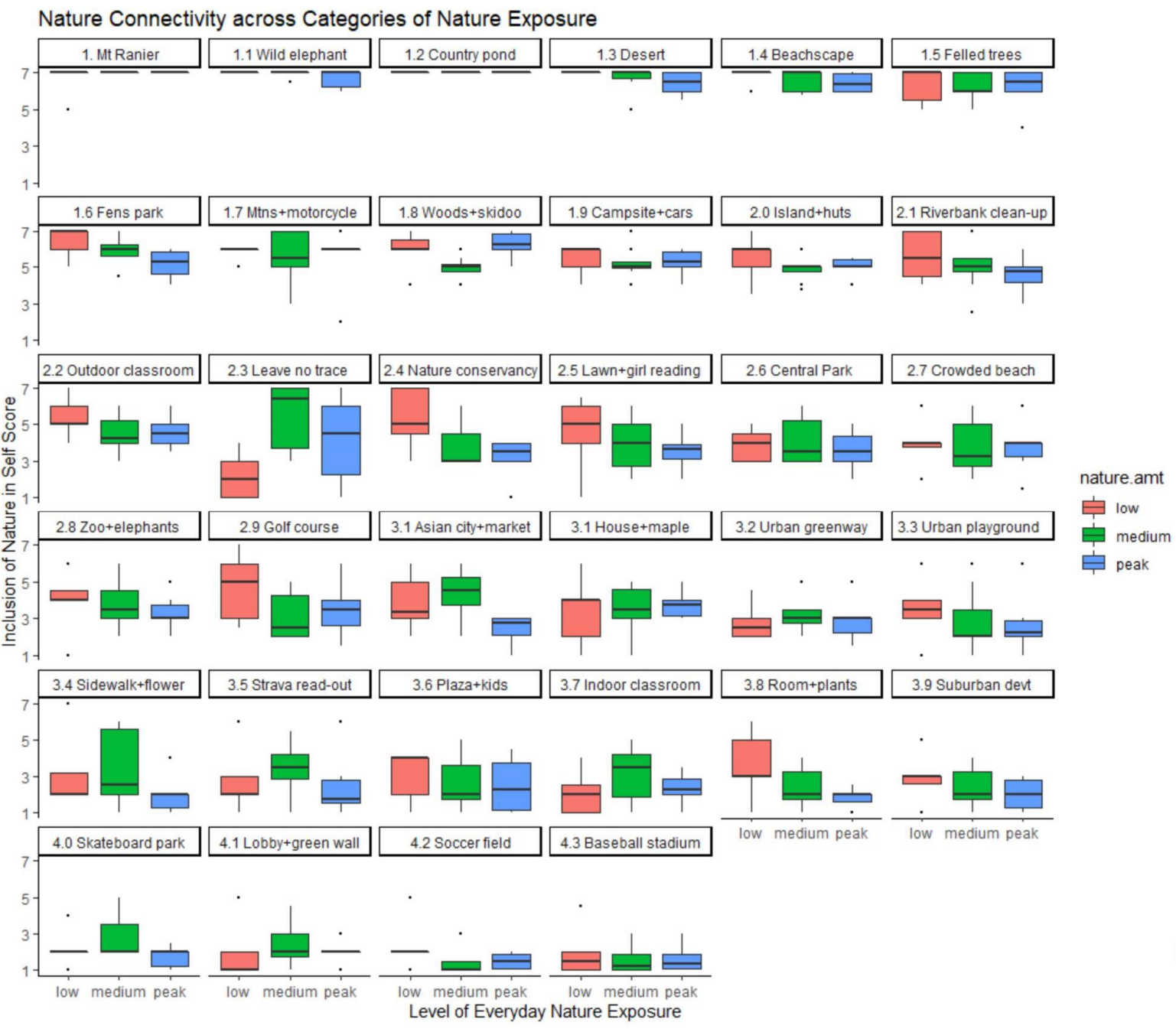

Figure 3. Nature photos were rated for NC by using the Inclusion of Nature in Self (INS) scale. The ratings are plotted by descending mean INS scores and by the categorical level. Focus groups were categorized by everyday nature exposure-low (red), medium (green), and peak (blue)—determined by the density of surrounding built and natural environments of the focus group areas and the participants' comments.

Categorizing the focus groups by everyday nature exposure did not generate linear mean scoring trends or predictably lower standard deviations (Table S1). However, the photo subgroups representing the lowest and highest everyday nature exposure bookended the rankings of the INS means (SD) among all subgroups [5.87(1.16); 3.24 (2.37)], which was reflective of the aggregate findings determined by the categorical exposure levels: low-4.43 (2.06); medium-4.25 (1.97); peak-3.92 (2.00), on a seven-point scale. Lownature-exposure groups viewed and evaluated scenes of nature in the built environment more favorably than those living and working in nature-rich environments. We removed two images, "Leave no Trace" and "Strava read-out," which evoked nature non-pictorially and whose symbolism was unfamiliar to individuals in the low-exposure groups. The removal of these images resulted in the determination of significant NC differences by the Kruskal-Wallis test as measured by the group-level nature exposure (Kruskal-Wallis $\chi 2=6.3445, \mathrm{df}=2, p=0.042)$. A pairwise comparison showed significance between the groups with the lowest and highest levels of nature exposure $(p=0.047)$ (Table 5). 

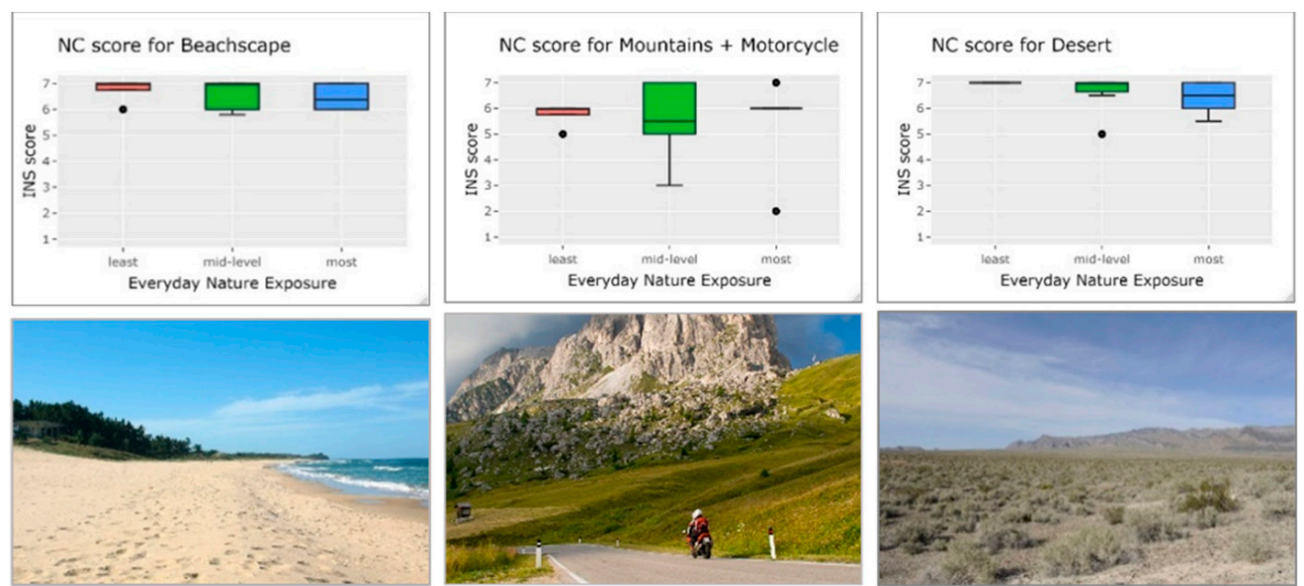

(a)
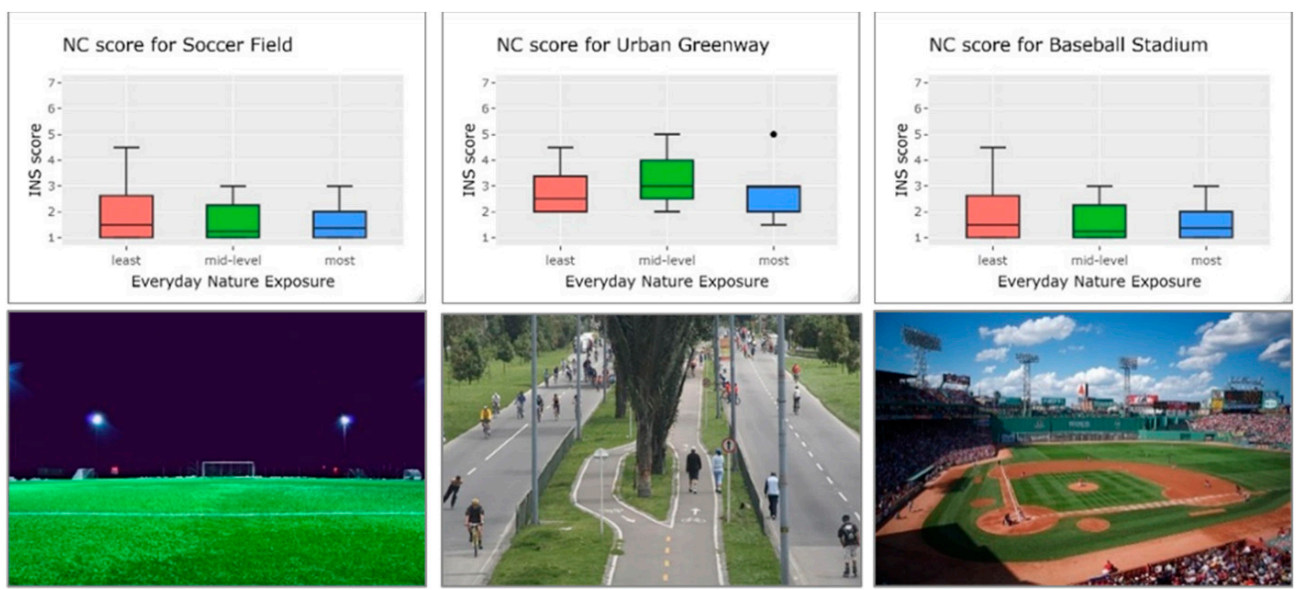

(b)
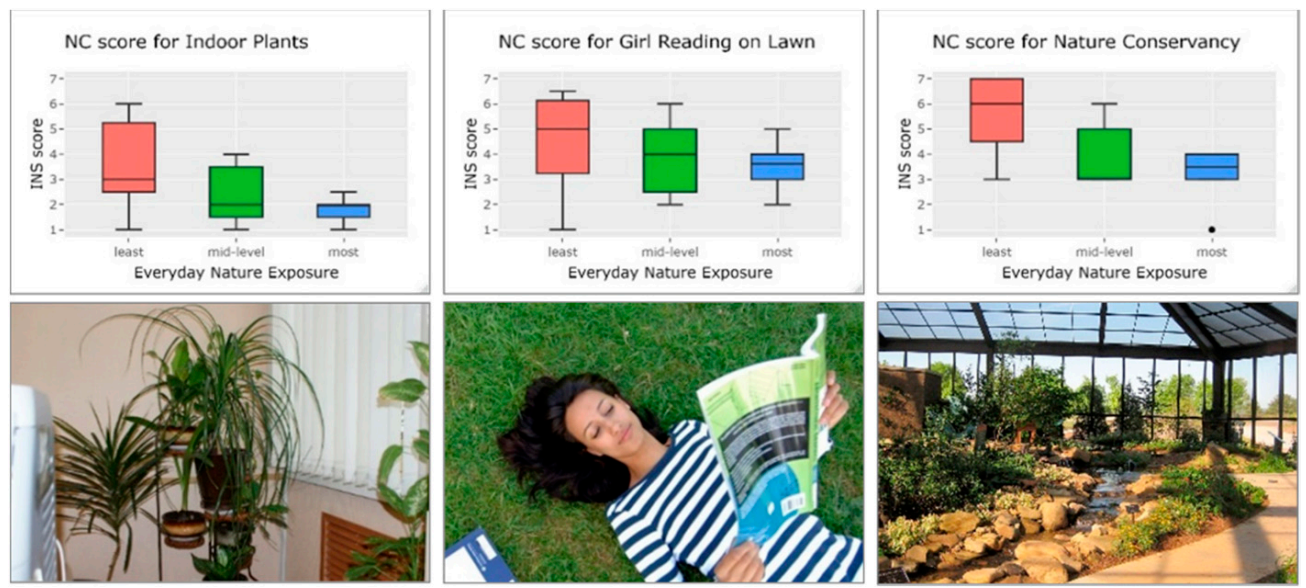

(c)

Figure 4. The results of the NC scoring by categorical levels of everyday nature exposure are paired with the type of nature scene. (a) Top: All focus groups assigned the highest mean scores of 6-7 to wild nature scenes; (b) Center: Urban outdoor scenes received the lowest mean scores of 1-3 from all exposure groups; (c) Bottom: Groups exposed to less nature connected to scenes of nature in built environments at consistently higher levels than the medium- or peak-exposure groups. 
Table 5. The Kruskal-Wallis rank sum test for a three-way group comparison shows that background levels of everyday nature exposure significantly predicted NC across the photo images. Pairwise tests yielded a significant difference in NC scores between the groups with the lowest vs. highest levels of everyday nature exposure.

\begin{tabular}{ccc}
\hline & \multicolumn{2}{c}{$p$-Values } \\
\hline Kruskal-Wallis rank sum test ${ }^{1}$ & & 0.042 \\
Kruskal-Wallis pair-wise tests & Low exposure & Medium exposure \\
Medium nature exposure & 0.314 & - \\
Peak nature exposure & 0.047 & 0.119 \\
\hline
\end{tabular}

${ }^{1}$ Kruskal-Wallis tests are assumed to be statistically significant at $p<0.05$.

\section{Discussion}

\subsection{Concurrence and Disagreement in the Findings}

From the individual and group conceptualizations of nature, we discerned three distinct prototypical classifications of how place, familiarity, and experience shape opinions of what constitutes 'nature'. The semi-structured discussion content differed from the NC scoring of nature-based scenes in some ways. The consensus process for the photo exercise provided the research team with the opportunity to examine vocalized reasons for complementarity and disagreement between the two data collection methods that individual scoring methods would not have revealed. Visual cues contained in the nature photos often reified participants' comments about nature attitudes that were voiced earlier [147]. As compared to abstracted nature concepts, the inclusion of pictorial images furnished "anchors of meaning" that focused on the contingent process of meaning-making around nature [118]. The range of photos also probed participants' treatment of the outdoors as a concept distinguishable from nature and how interaction with familiar quasi-natured outdoor settings influenced the NC responses. Most groups did distinguish nature from the outdoors under both methods, further contextualizing each concept according to the specific setting.

Natural vegetation-not parks or outdoor recreational venues-appeared to trigger $\mathrm{NC}$ among all groups. This observation suggests inherent biophilic connections, which is consistent with the existing literature on biophilia, which creates propensities to seek out nature as its own end $[60,148,149]$. These results should inform planning of inclusive outdoor spaces to appeal to the biophilic tendencies underlying many psychological health responses to nature. Further research may investigate how nature-based interventions in urban parks, e.g., sensory gardens, would compare with enhancements to park amenities in, first, enticing individuals into nature and, second, comparing affective changes that follow nature vs. outdoor contact. Knowing how these outcomes differ can inform the design of schoolyards, parks, and community centers for children, adults, and seniors, respectively, who depend on municipal infrastructure for their contact with nature. The latent aspects of contact with nature discussed here-inter alia, wildness and biophilic appeal—can be incorporated into public infrastructure planning to make health and wellbeing explicit as a means of reducing social disadvantage $[24,122]$ through the use of natural systems and processes in designing built environments [150]. If we choose to accept nature contact as a "universal primary need, not a cultural amenity" [151], biophilic design can mediate this needed interaction with otherwise low-natured environments [152-154].

Discrepant NC scores were most apparent in scenes depicting nature in built environment settings. "We discovered that people's personal experience is divided as a group as far as the artificially created nature vs. those that were wild or unconstructed (not designed). My personal preferences made me hesitate about feeling a connection to nature prima facie" (Female, mid-40s, Berkeley). Urban low-nature-exposure groups recorded higher mean NC and full acceptance of nature in built environment contexts. The stronger affinity for scenes such as "Suburban development", "Room with plants", and "Golf course" among these groups may reflect their greater sensitivity to vegetation in urban environments where urban ecology is low. The presence of several teachers in 
the medium-exposure groups perhaps influenced these groups' higher NC responses to figurative nature associations, e.g., "Indoor classroom" and "Dandelion in Sidewalk." Habituation to nature-rich environments among the high-exposure individuals may explain their rejection of urban-nature-based scenes, except as non-natured agents meant to bring people outdoors. The medium- and high-exposure groups debated the tolerance of-and annoyance with-man-made or artificial elements in otherwise natural settings. "The artificiality of nature was definitely something we were divided on" (female, late 30s, USG conservationist). Comments from high-nature-exposure individuals supported prior findings that the presence of the artificial in nature impedes stress reduction [155], leaving open opportunities to investigate stress responses to nature among underexposed populations. The low-nature-exposure groups, who also represented the youngest and lowest SES strata, were the most vocal in discussing environmental degradation and climate change. These groups, more than the medium- and high-exposure groups, connected readily to scenes associated with conservation and environmental education, e.g., "Riverbank clean-up", "Nature conservancy", and "Outdoor classroom." Previous research demonstrated that concern for nature and social justice dovetails with climate change activism among youth and young environmentalists [156-158]. The low-exposure groups also highly scored multisensorial images of urban nature, e.g., "Lawn with girl reading" and "Plaza fountain with children", emphasizing the subjects' haptic connection with nature: "The fact that she's in the open air on a lawn, instead of the library, that is a literal connection of touching nature since she's laying in the grass" (female, mid-20s, Colombia) and "Her whole head is in the grass, connecting physically with nature" (female, college age, urban Atlanta). Conversely, an individual in the high-exposure group rejected the scenario's very likelihood altogether: "Sitting in a city context, I feel like this is not something you would normally see in a city" (female, later 20s, Tempe).

Our study revealed several other findings besides those already present in the literature. First, all participant groups, regardless of their nature exposure, responded with equal connection to wild nature scenes and equal disconnection to scenes of low nature content. Such consistent response patterning suggests an intuitive biophilic response to what is and is not nature $[47,159]$ that is rooted in a genetic human propensity toward nature [160], not just in first-hand experiences in nature. Two recent literature reviews independently concluded that humans have a "fundamental psychological need" for NR [51,52], with empirical evidence supporting NC as a "primitive belief" [161].

Second, the dissatisfaction with being outdoors versus in wild nature first expressed in the focus groups was validated by the low NC scores assigned to open-air "artificial" recreation sites in the photo exercise. Urban low-nature-exposure individuals described their nature experiences during the focus group discussions as looking at the sky or playing after-school football, yet did not connect with these same elements when they envisioned themselves as spectators. In fact, photos of outdoor facilities instilled NC only when participants placed themselves as actors in the scenes, e.g., "Campsite", "Winter Snowmobiling", and "The Fens", rather than as on-lookers, e.g., in "Plaza fountain with children" or "Turfgrass." Surprisingly, all three groups responded tepidly (mean INS score $=3.08, \mathrm{SD}=1.10$ ) to "Urban Greenway", with its combined green exercise and amenities offerings. These findings suggest that urban greenspace must invite interactions by city residents in order to be usable for purposes of nature contact and not just plentiful as an NDVI measurement.

Third, the higher INS scores for built environment settings given the by low- and medium-exposure groups but not the high-exposure group signaled that context saliently matters when evaluating nature. Photos that showed natural elements "unnaturally" introduced into artificial or built settings, e.g., "Lobby green wall" and "Urban Playground", failed to connect any group to nature. However, the low-exposure groups assigned higher $\mathrm{NC}$ scores to scenes of built environments where nature plausibly enhanced structural urban drabness, e.g., "Outdoor classroom" and "Farmers' market". Individuals may be instinctively primed to recognize appropriate translations of biophilic properties but reject others that are less well-suited. 
Taken together, these findings support the idea of different conceptualizations of nature among prototypical exposure groups and the meanings that nature use holds for them. The mixed methods used in this study suggest that cultural sets, which include cumulative nature experiences, shape one's definition of nature, but not one's intuitive relatedness to nature. Eclectic approaches such as those used here can often expand data analyses to reveal overlooked pathways toward positive nature engagement. Our use of photo imagery as an analytical tool to validate qualitative discussion commentary indicated where along the spectrum of built and natural environments perceptual differences emerged. This was particularly true when the principal conduit of nature familiarity for many city dwellers was the urban setting. The deployment of urban ecology and biophilic design may be useful for car-less urban dwellers for whom natural environments outside expanding city limits have become increasingly inaccessible. At the same time, programs that promote nature experiences of a larger scale and duration and that are free of the visual distractions of artificial built features, which are associated with stress, may appeal to those with low everyday nature exposure if appropriate introductions are made available.

\subsection{Implications of Findings}

The results of this process ought to influence future nature and health studies to consider more nuanced interpretations of how individual participants respond to experiences in nature. To the expanding criteria set for measuring nature contact in nature-health research, we might add "meaning", i.e., what does nature contact, statically measured, mean for individuals with varying nature relationships within a specific context? Alternatively, if we continue to assess nature-health as a binary exposure-outcome relationship, then cultural sets, which include prototypical exposure, formative introductions, and relatedness to nature, could be added to specify characteristics of those in our study population.

Our findings suggest that a nature construct as expressed by our participants appears bounded by previous nature-based experiences, degrees of contact with biophilic quality, and circumscribed expectations. This research indicates that individuals with low- and high-nature backgrounds regard nature differently when lower-exposure individuals are both urban and of a low SES. Urban residents who are not of a low SES tend to seek out larger landscapes for recreation and, therefore, did not respond with the same affinity to nature found in built environments as did individuals living in nature-poor neighborhoods. The more animated expressions of NC for lower thresholds of urban vegetation among the low-exposure groups may signal an unmet biophilic need stemming from low nature supply rather than from viewing nature differently. Future studies might examine the effects of nature contact among individuals expressing different levels of demand for nature given fixed vegetation supplies. Nonetheless, how individuals conceptualize nature may be less important than their intrinsic biophilic affinity toward natured spaces that are both familiar and unfamiliar.

\subsection{Study Strengths and Limitations}

The participants' self-selection into the four focus groups that were recruited through Facebook and further scheduling availability likely conditioned the generalizability of the results, and we were not able to reach some desired demographic groups. Young adults of color mostly represented the low SES stratum, so we failed to capture inter-generational diversity in our sampling. The 34 nature images selected for the photo exercise may have missed some inherent conceptual meanings. The process of assigning nature scores by group rather than individually implies that some respondents' opinions may have been swayed by or lost to group dynamics. The advantage of using photos as proxies of various nature-based settings was muted by not capturing direct physical presence in nature to probe the biophilic effect that underlies nature connectivity.

However, our study's strengths of design and representation provided for multiple cultural perspectives that are uncommon even in qualitative research. The use of two rather than a single participatory research tool—focus group discussions operationalized with 
photo imagery-allowed for comparison of quantitative and qualitative results in order to identify and interpret divergent findings. While we are not exhaustively explaining the phenomenon of nature-seeking, we elicit a good description of the diversity of experiencing nature. The study's design allowed us to analyze representative observations by the sampled groups, and the semi-structured format elicited extensive qualitative data, which is not possible with survey instruments of the requisite brevity.

\section{Conclusions}

This study investigated how individuals with diverse sociodemographic attributes conceptualize and connect with nature. Our preliminarily findings projected a baseline biophilic affinity for all individuals for what is and is not nature overlain by circumstantial responses that were closely aligned with built environment settings. This research also suggests it is not enough to know that sociodemographics predispose individuals to regard nature differently, but it is also necessary to know the contexts and ways in which these differences surface so as to shape opportunities for interacting with nature as a prospect for the enhancement of health and wellbeing. Perhaps it is not necessary to define nature as much as to capture autonomic responses to naturalistic impulses when translating research into practice. Interpretations of what is and is not "known" to be nature can be impartially organized by experiences, locations, and cultural sets to sharpen nature exposure constructs in order to assess their associated health outcomes.

Supplementary Materials: The following are available online at https://www.mdpi.com/article/10 .3390/su132011266/s1: Table S1: Focus Group Characteristics. Figure S1: Focus Group Locations. Table S2: Topic Guide for Focus Group Discussions. Figure S2: Full array of nature photo images used to assess nature connectedness.

Author Contributions: Conceptualization, L.P.T. and J.D.S.; methodology, L.P.T., J.G.C.L. and J.D.S.; software, L.P.T. and J.G.C.L.; formal analysis, L.P.T., J.D.S., J.T.C. and P.J.C.; investigation, L.P.T.; data curation, L.P.T.; writing_-original draft preparation, L.P.T.; writing—review and editing, J.T.C. and J.D.S.; visualization, L.P.T.; supervision, J.D.S., J.T.C. and J.G.C.L.; project administration, L.P.T. and J.G.C.L.; funding acquisition, L.P.T. and J.D.S. All authors have read and agreed to the published version of the manuscript.

Funding: We thank the REI Cooperative for their sponsorship of the Department of Environmental Health's research on nature exposure and health at the Harvard T.H. Chan School of Public Health. L.P.T. additionally received training support from NRSA T32-ES007069.

Institutional Review Board Statement: The study was conducted according to the guidelines of the Declaration of Helsinki and approved by the Institutional Review Board of Harvard T.H. Chan School of Public Health (protocol code 19-1419 on 28 August 2019).

Informed Consent Statement: Informed consent was obtained from all subjects involved in the study.

Data Availability Statement: The data are presented in the paper.

Acknowledgments: The authors wish to thank Matthew Browning for his helpful insights on quantitative data presentation. We also thank JPB Environmental Health Fellows Christina Hemphill Fuller and Kirk Jalbert for their assistance in organizing and recruiting student focus groups, Genna Heath for her assistance in organizing interviews with Facebook ad respondents, and all focus group participants for their time and interest.

Conflicts of Interest: The authors declare no conflict of interest. The funders had no role in the design of the study; in the collection, analyses, or interpretation of data; in the writing of the manuscript, or in the decision to publish the results.

\section{References}

1. Furness, E. Understanding the lived experience of connection to nature. Conserv. Sci. Pract. 2021, 3, e440.

2. Martin, L.; White, M.P.; Hunt, A.; Richardson, M.; Pahl, S.; Burt, J. Nature contact, nature connectedness and associations with health, wellbeing and pro-environmental behaviours. J. Env. Psychol. 2020, 68, 101389. [CrossRef] 
3. Dean, J.; Shanahan, D.; Bush, R.; Gaston, K.; Lin, B.; Barber, E.; Franco, L.; Fuller, R.A. Is Nature Relatedness Associated with Better Mental and Physical Health? Int. J. Environ. Res. Public Health 2018, 15, 1371. [CrossRef]

4. Nisbet, E.K.; Zelenski, J.; Murphy, S.A. Happiness is in our Nature: Exploring Nature Relatedness as a Contributor to Subjective Well-Being. J. Happiness Stud. 2011, 12, 303-322. [CrossRef]

5. Mayer, F.S.; Frantz, C.M.; Bruehlman-Senecal, E.; Dolliver, K. Why Is Nature Beneficial? The Role of Connectedness to Nature. Env. Behav. 2009, 41, 607-643. [CrossRef]

6. Cervinka, R.; Röderer, K.; Hefler, E. Are nature lovers happy? On various indicators of well-being and connectedness with nature. J. Health Psychol. 2012, 17, 379-388. [CrossRef] [PubMed]

7. Capaldi, C.A.; Dopko, R.L.; Zelenski, J.M. The relationship between nature connectedness and happiness: A meta-analysis. Front. Psychol. 2014, 5, 976. [CrossRef] [PubMed]

8. Lee, J.-H.; Lee, S.-J. Nature experience influences nature aversion: Comparison of South Korea and Germany. Soc. Behav. Pers. Int. J. 2018, 46, 161-176. [CrossRef]

9. Reddon, J.R.; Durante, S.B. Nature exposure sufficiency and insufficiency: The benefits of environmental preservation. Med. Hypotheses 2018, 110, 38-41. [CrossRef]

10. Taylor, D.E. College Students and Nature: Differing Thoughts of Fear, Danger, Disconnection, and Loathing. Environ. Manag. 2019, 64, 79-96. [CrossRef]

11. Anderson, K.R. “Do Not Play" Outdoor Advisories: Examining the Impact of Soil Lead Contamination in Urban Communities. Ph.D. Thesis, Indiana University, Indiana, IN, USA, 2021.

12. Sullivan, M.; Green, D. Toward eliminating children's lead exposure: A comparison of policies and their outcomes in three lead producing and using countries. Env. Res Lett 2020, 10, 103008. [CrossRef]

13. Zajchowski, C.A.B.; Rose, J. Sensitive Leisure: Writing the Lived Experience of Air Pollution. Leis. Sci. 2020, 42, 1-14. [CrossRef]

14. Oh, R.Y.R.; Fielding, K.S.; Le Nghiem, T.P.; Chang, C.-C.; Shanahan, D.F.; Gaston, K.J.; Carrasco, R.L.; Fuller, R.A. Factors influencing nature interactions vary between cities and types of nature interactions. People Nat. 2021, 3, 405-417. [CrossRef]

15. Richards, D.R.; Fung, T.K.; Leong, R.A.T.; Sachidhanandam, U.; Drillet, Z.; Edwards, P.J. Demographic biases in engagement with nature in a tropical Asian city. PLoS ONE 2020, 15, e0231576. [CrossRef] [PubMed]

16. Cox, D.T.C.; Shanahan, D.F.; Hudson, H.L.; Fuller, R.A.; Anderson, K.; Hancock, S.; Gaston, K.J. Doses of Nearby Nature Simultaneously Associated with Multiple Health Benefits. Int. J. Environ. Res. Public Health 2017, 14, 172. [CrossRef] [PubMed]

17. Shanahan, D.F.; Cox, D.T.C.; Fuller, R.A.; Hancock, S.; Lin, B.B.; Anderson, K.; Bush, R.; Gaston, K.J. Variation in experiences of nature across gradients of tree cover in compact and sprawling cities. Landsc. Urban Plan. 2017, 157, 231-238. [CrossRef]

18. Browning, M.H.E.M.; Rigolon, A. Do Income, Race and Ethnicity, and Sprawl Influence the Greenspace-Human Health Link in City-Level Analyses? Findings from 496 Cities in the United States. Int. J. Environ. Res. Public Health 2018, 15, 1541. [CrossRef]

19. Rigolon, A. A complex landscape of inequity in access to urban parks: A literature review. Landsc. Urban Plan. 2016, 153, 160-169. [CrossRef]

20. Virden, R.; Walker, G.J. Ethnic/Racial and Gender Variations Among Meanings Given to, and Preferences for, the Natural Environment. Leis. Sci. 1999, 21, 219-239.

21. Department of the Interior, National Park Service, Floyd DrM. Race, Ethnicity and Use of the National Park System. All US Government Documents (Utah Regional Depository). 1999. Available online: https://digitalcommons.usu.edu/govdocs/427. (accessed on 14 August 2021).

22. Roe, J.; Aspinall, P.A.; Thompson, C.W. Understanding Relationships between Health, Ethnicity, Place and the Role of Urban Green Space in Deprived Urban Communities. Int. J. Environ. Res. Public Health 2016, 13, 681. [CrossRef]

23. Taylor, D.E. Understanding Black, Asian, Latinx, and White College Students' Views of Nature: Frequent Thoughts About Wild, Remote, Rural, and Urban Landscapes. Am. Behav. Sci. 2021, 00027642211013403. [CrossRef]

24. Frumkin, H.; Bratman, G.N.; Breslow, S.J.; Cochran, B.; Kahn, P.H.; Lawler, J.J.; Levin, P.S.; Tandon, P.S.; Varanasi, U.; Wolf, K.L.; et al. Nature Contact and Human Health: A Research Agenda. Env. Health Perspect 2017, 125, 075001. [CrossRef]

25. McClure, M.T. The Greek Conception of Nature. Philos. Rev. 1934, 43, 109-124. [CrossRef]

26. Ulrich, R.S. Aesthetic and Affective Response to Natural Environment. In Behavior and the Natural Environment; Altman, I., Wohlwill, J.F., Eds.; Springer: Boston, MA, USA, 1983; Volume 13, pp. $29-44$.

27. Ulrich, R.S. Human responses to vegetation and landscapes. Landsc. Urban Plan. 1986, 13, 29-44. [CrossRef]

28. Herzog, T.R. A cognitive analysis of preference for urban nature. J. Environ. Psychol. 1989, 9, 27-43. [CrossRef]

29. Altman, I.; Wohlwill, J.F. Behavior and the Natural Environment; Plenum Press: New York, NY, USA, 1983.

30. Talbot, J.F.; Kaplan, R. Needs and fears: The response to trees and nature in the inner city. J. Arboric. 1984, 8, $222-228$.

31. Carr, D.S.; Williams, D.R. Understanding the Role of Ethnicity in Outdoor Recreation Experiences. J. Leis. Res. 1993, 25, 22-38. [CrossRef]

32. Schroeder, H.W. Variations in the perception of urban forest recreation sites. Leis. Sci. 1983, 5, 221-230. [CrossRef]

33. Kaplan, R.; Kaplan, S.; Brown, T. Environmental Preference: A Comparison of Four Domains of Predictors. Env. Behav. 1989, 21, 509-530. [CrossRef]

34. Kaplan, R.; Talbot, J.F. Ethnicity and preference for natural settings: A review and recent findings. Landsc. Urban Plan. 1988, 15, 107-117. [CrossRef] 
35. Parks, S.E.; Housemann, R.A.; Brownson, R.C. Differential correlates of physical activity in urban and rural adults of various socioeconomic backgrounds in the United States. J. Epidemiol. Community Health 2003, 57, 29-35. [CrossRef] [PubMed]

36. Larson, L.R.; Szczytko, R.; Bowers, E.P.; Stephens, L.E.; Stevenson, K.T.; Floyd, M.F. Outdoor Time, Screen Time, and Connection to Nature: Troubling Trends Among Rural Youth? Env. Behav. 2019, 51, 966-991. [CrossRef]

37. Tandon, P.S.; Kuehne, L.M.; Olden, J.D. Trends and Knowledge Gaps in the Study of Nature-Based Participation by Latinos in the United States. Int. J. Environ. Res. Public Health 2018, 15, 1287. [CrossRef] [PubMed]

38. Izenstark, D.; Crossman, K.A.; Middaugh, E. Examining family-based nature activities among Latinx students: Contexts for reinforcing family relationships and cultural heritage. Ann. Leis. Res. 2021, 1-21. [CrossRef]

39. Casey, J.A.; Morello-Frosch, R.; Mennitt, D.J.; Fristrup, K.; Ogburn, E.L.; James, P. Race/Ethnicity, Socioeconomic Status, Residential Segregation, and Spatial Variation in Noise Exposure in the Contiguous United States. Env. Health Perspect. 2017, 125, 077017. [CrossRef]

40. Payne, L.L.; Mowen, A.J.; Orsega-Smith, E. An Examination of Park Preferences and Behaviors Among Urban Residents: The Role of Residential Location, Race, and Age. Leis. Sci. 2002, 24, 181-198. [CrossRef]

41. Sister, C.; Wolch, J.; Wilson, J. Got green? addressing environmental justice in park provision. GeoJournal 2010, 75, 229-248. [CrossRef]

42. Jakstis, K.; Fischer, L.K. Urban Nature and Public Health: How Nature Exposure and Sociocultural Background Relate to Depression Risk. Int. J. Environ. Res. Public Health 2021, 18, 9689. [CrossRef] [PubMed]

43. Lorentzen, C.A.N.; Viken, B. Immigrant women, nature and mental health. Int. J. Migr. Health Soc. Care 2020, 16, 359-372. [CrossRef]

44. Lovelock, K.; Lovelock, B.; Jellum, C.; Thompson, A. In search of belonging: Immigrant experiences of outdoor nature-based settings in New Zealand. Leis. Stud. 2011, 30, 513-529. [CrossRef]

45. Burns, R.C.; Graefe, A.R. Constraints to Outdoor Recreation: Exploring the Effects of Disabilities on Perceptions and Participation. J. Leis. Res. 2007, 39, 156-181. [CrossRef]

46. Wilson, E.O. Biophilia, Revised ed.; Harvard University Press: Cambridge, MA, USA, 1984; p. 157.

47. Kellert, S.R.; Wilson, E.O. The Biophilia Hypothesis; Island Press: Washington, DC, USA, 1993; p. 493.

48. Haluza, D.; Simic, S.; Höltge, J.; Cervinka, R.; Moshammer, H. Connectedness to Nature and Public (Skin) Health Perspectives: Results of a Representative, Population-Based Survey among Austrian Residents. Int. J. Env. Res. Public Health 2014, 11, 1176-1191. [CrossRef] [PubMed]

49. Richardson, M.; Hunt, A.; Hinds, J.; Bragg, R.; Fido, D.; Petronzi, D.; Barbett, L.; Clitherow, T.; White, M. A Measure of Nature Connectedness for Children and Adults: Validation, Performance, and Insights. Sustainability 2019, 11, 3250. [CrossRef]

50. Nisbet, E.K.; Zelenski, J.M.; Grandpierre, Z. Mindfulness in Nature Enhances Connectedness and Mood. Ecopsychology 2019, 11, 81-91. [CrossRef]

51. Baxter, D.E.; Pelletier, L.G. Is nature relatedness a basic human psychological need? A critical examination of the extant literature. Can. Psychol. Can. 2019, 60, 21-34. [CrossRef]

52. Hurly, J.; Walker, G.J. Nature in our lives: Examining the human need for nature relatedness as a basic psychological need. J. Leis. Res. 2019, 50, 290-310. [CrossRef]

53. Nisbet, E.K.; Zelenski, J.M.; Murphy, S.A. The Nature Relatedness Scale: Linking Individuals' Connection with Nature to Environmental Concern and Behavior. Env. Behav. 2009, 41, 715-740. [CrossRef]

54. Molina-Cando, M.J.; Escandón, S.; Van Dyck, D.; Cardon, G.; Salvo, D.; Fiebelkorn, F.; Andrade, S.; Ochoa-Avilés, C.; García, A.; Brito, J.; et al. Nature relatedness as a potential factor to promote physical activity and reduce sedentary behavior in Ecuadorian children. PLoS ONE 2021, 16, e0251972. [CrossRef]

55. Kals, E.; Schumacher, D.; Montada, L. Emotional Affinity toward Nature as a Motivational Basis to Protect Nature. Env. Behav. 1999, 31, 178-202. [CrossRef]

56. Müller, M.; Kals, E.; Pansa, R. Adolescents' Emotional Affinity toward Nature: A Cross-Societal Study. J. Dev. Process. 2009, 4, 59.

57. Ives, C.D.; Giusti, M.; Fischer, J.; Abson, D.; Klaniecki, K.; Dorninger, C.; Laudan, J.; Barthel, S.; Abernethy, P.; Martin-Lopez, B.; et al. Human-nature connection: A multidisciplinary review. Curr. Opin. Env. Sustain. 2017, 26, 106-113. [CrossRef]

58. Martyn, P.; Brymer, E. The relationship between nature relatedness and anxiety. J. Health Psychol. 2016, 21, 1436-1445. [CrossRef]

59. Lawton, E.; Brymer, E.; Clough, P.; Denovan, A. The Relationship between the Physical Activity Environment, Nature Relatedness, Anxiety, and the Psychological Well-being Benefits of Regular Exercisers. Front. Psychol. 2017, 8, 1058. [CrossRef] [PubMed]

60. Berto, R.; Barbiero, G.; Barbiero, P.; Senes, G. An Individual's Connection to Nature Can Affect Perceived Restorativeness of Natural Environments. Some Observations about Biophilia. Behav. Sci. 2018, 8, 34. [CrossRef] [PubMed]

61. Schultz, P.W. Inclusion with Nature: The Psychology of Human-Nature Relations. In Psychology of Sustainable Development; Schmuck, P., Schultz, W.P., Eds.; Springer: Boston, MA, USA, 2002; Volume 24, pp. 503-515.

62. Mayer, F.S.; Frantz, C.M. The connectedness to nature scale: A measure of individuals' feeling in community with nature. J. Env. Psychol. 2004, 24, 503-515. [CrossRef]

63. Nisbet, E.K.; Zelenski, J.M. The NR-6: A new brief measure of nature relatedness. Front. Psychol. 2013, 4, 813. [CrossRef] [PubMed]

64. Greenwald, A.G.; McGhee, D.E.; Schwartz, J.L.K. Measuring individual differences in implicit cognition: The implicit association test. J. Personal. Soc. Psychol. 1998, 74, 1464-1480. [CrossRef] 
65. Tam, K.-P. Dispositional Empathy with Nature. J. Env. Psychol. 2013, 35, 92-104. [CrossRef]

66. Perkins, H.E. Measuring love and care for nature. J. Env. Psychol. 2010, 30, 455-463. [CrossRef]

67. Keaulana, S.; Kahili-Heede, M.; Riley, L.; Park, M.L.N.; Makua, K.L.; Vegas, J.K.; Antonio, M.C. A Scoping Review of Nature, Land, and Environmental Connectedness and Relatedness. Int. J. Env. Res. Public Health 2021, 18, 5897. [CrossRef]

68. Milfont, T.L.; Duckitt, J. The structure of environmental attitudes: A first- and second-order confirmatory factor analysis. J. Env. Psychol. 2004, 24, 289-303. [CrossRef]

69. Stern, P.C.; Dietz, T.; Guagnano, G.A. A Brief Inventory of Values. Educ. Psychol. Meas. 1998, 58, 984-1001. [CrossRef]

70. DeVille, N.V.; Tomasso, L.P.; Stoddard, O.P.; Wilt, G.E.; Horton, T.H.; Wolf, K.L.; Brymer, E.; Kahn, P.; James, P. Time Spent in Nature Is Associated with Increased Pro-Environmental Attitudes and Behaviors. Int. J. Env. Res. Public Health 2021, 18, 7498. [CrossRef]

71. Olivos, P.; Aragonés, J.I.; Amérigo, M. The Connectedness to Nature Scale and Its Relationship with Environmental Beliefs And Identity. Int. J. Hisp. Psychol. 2011, 4, 5-19.

72. Larson, L.R.; Whiting, J.W.; Green, G.T. Exploring the influence of outdoor recreation participation on pro-environmental behaviour in a demographically diverse population. Local Env. 2011, 16, 67-86. [CrossRef]

73. Rosa, C.D.; Profice, C.C.; Collado, S. Nature Experiences and Adults' Self-Reported Pro-environmental Behaviors: The Role of Connectedness to Nature and Childhood Nature Experiences. Front. Psychol. 2018, 9, 1055. [CrossRef]

74. Rosa, C.D.; Collado, S. Experiences in Nature and Environmental Attitudes and Behaviors: Setting the Ground for Future Research. Front. Psychol. 2019, 10, 1-9. [CrossRef] [PubMed]

75. Alcock, I.; White, M.P.; Pahl, S.; Duarte-Davidson, R.; Fleming, L.E. Associations between pro-environmental behaviour and neighbourhood nature, nature visit frequency and nature appreciation: Evidence from a nationally representative survey in England. Environ. Int. 2020, 136, 105441. [CrossRef] [PubMed]

76. Broom, C. Exploring the Relations Between Childhood Experiences in Nature and Young Adults' Environmental Attitudes and Behaviours. Aust. J. Environ. Educ. 2017, 33, 34-47. [CrossRef]

77. Chawla, L.; Derr, V. The development of conservation behaviors in childhood and youth. In The Oxford Handbook of Environmental and Conservation Psychology; Oxford University Press: New York, NY, USA, 2012; pp. 527-555.

78. Thompson, C.W.; Aspinall, P.; Montarzino, A. The Childhood Factor: Adult Visits to Green Places and the Significance of Childhood Experience. Env. Behav. 2008, 40, 111-143. [CrossRef]

79. Hughes, J.; Richardson, M.; Lumber, R. Evaluating connection to nature and the relationship with conservation behaviour in children. J. Nat. Conserv. 2018, 45, 11-19. [CrossRef]

80. Fränkel, S.; Sellmann-Risse, D.; Basten, M. Fourth graders' connectedness to nature-Does cultural background matter? J. Env. Psychol. 2019, 66, 101347. [CrossRef]

81. Taylor, D.E. Racial and Ethnic Differences in Connectedness to Nature and Landscape Preferences Among College Students. Env. Justice 2018, 11, 118-136. [CrossRef]

82. Ravenscroft, N.; Markwell, S. Ethnicity and the integration and exclusion of young people through urban park and recreation provision. Manag. Leis. 2000, 5, 135-150. [CrossRef]

83. Theriault, D.; Mowatt, R.A. Both Sides Now: Transgression and Oppression in African Americans' Historical Relationships with Nature. Leis. Sci. 2020, 42, 15-31. [CrossRef]

84. Puhakka, S.; Pyky, R.; Lankila, T.; Kangas, M.; Rusanen, J.; Ikäheimo, T.M.; Koivumaa-Honkanen, H.; Korpelainen, R. Physical Activity, Residential Environment, and Nature Relatedness in Young Men-A Population-Based MOPO Study. Int. J. Env. Res. Public Health 2018, 15, 2322. [CrossRef] [PubMed]

85. Byrne, J. When green is White: The cultural politics of race, nature and social exclusion in a Los Angeles urban national park. Geoforum 2012, 43, 595-611. [CrossRef]

86. Smiley, K.T.; Sharma, T.; Steinberg, A.; Hodges-Copple, S.; Jacobson, E.; Matveeva, L. More Inclusive Parks Planning: Park Quality and Preferences for Park Access and Amenities. Env. Justice 2016, 9, 1-7. [CrossRef]

87. Jennings, V.; Gaither, C.J. Approaching Environmental Health Disparities and Green Spaces: An Ecosystem Services Perspective. Int. J. Env. Res. Public Health 2015, 12, 1952-1968. [CrossRef]

88. Finney, C. Black Faces, White Spaces: Reimagining the Relationship of African Americans to the Great Outdoors; UNC Press Books: Chapel Hill, NC, USA, 2014; p. 194.

89. Stapleton, S.R. Toward critical environmental education: A standpoint analysis of race in the American environmental context. Env. Educ. Res. 2020, 26, 155-170. [CrossRef]

90. Davis, J. Black faces, black spaces: Rethinking African American underrepresentation in wildland spaces and outdoor recreation. Env. Plan. E Nat. Space 2019, 2, 89-109. [CrossRef]

91. Kabisch, N. The Influence of Socio-economic and Socio-demographic Factors in the Association Between Urban Green Space and Health. In Biodiversity and Health in the Face of Climate Change; Marselle, M.R., Stadler, J., Korn, H., Irvine, K.N., Bonn, A., Eds.; Springer International: Cham, Switzerland, 2019; pp. 91-120. [CrossRef]

92. Lindsay, J.J.; Ogle, R.A. Socioeconomic Patterns of Outdoor Recreation Use Near Urban Areas. J. Leis. Res. 1972, 4, 19-24. [CrossRef]

93. Eyre, E.L.J.; Duncan, M.J.; Birch, S.L.; Cox, V.; Blackett, M. Physical activity patterns of ethnic children from low socio-economic environments within the UK. J. Sports Sci. 2015, 33, 232-242. [CrossRef] 
94. Kabisch, N.; Van den Bosch, M.; Lafortezza, R. The health benefits of nature-based solutions to urbanization challenges for children and the elderly-A systematic review. Env. Res. 2017, 159, 362-373. [CrossRef]

95. Su, J.G.; Jerrett, M.; de Nazelle, A.; Wolch, J. Does exposure to air pollution in urban parks have socioeconomic, racial or ethnic gradients? Env. Res. 2011, 111, 319-328. [CrossRef] [PubMed]

96. Banzhaf, S.; Ma, L.; Timmins, C. Environmental Justice: The Economics of Race, Place, and Pollution. J. Econ. Perspect. 2019, 33, 185-208. [CrossRef] [PubMed]

97. Rosa, C.D.; Larson, L.R.; Collado, S.; Cloutier, S.; Profice, C.C. Gender Differences in Connection to Nature, Outdoor Preferences, and Nature-Based Recreation Among College Students in Brazil and the United States. Leis. Sci. 2020, 1-21. [CrossRef]

98. Wesely, J.K.; Gaarder, E. The Gendered "Nature” of the Urban Outdoors: Women Negotiating Fear of Violence. Gend. Soc. 2004, 18, 645-663. [CrossRef]

99. Shirazi, M.R. Mapping neighbourhood outdoor activities: Space, time, gender and age. J. Urban Des. 2019, 24, 715-737. [CrossRef]

100. Tang, I.-C.; Tsai, Y.-P.; Lin, Y.-J.; Chen, J.-H.; Hsieh, C.-H.; Hung, S.-H.; Sullivan, W.; Tang, H.-F.; Chang, C.-Y. Using functional Magnetic Resonance Imaging (fMRI) to analyze brain region activity when viewing landscapes. Landsc. Urban Plan. 2017, 162, 137-144. [CrossRef]

101. Kalivoda, O.; Vojar, J.; Skřivanová, Z.; Zahradník, D. Consensus in landscape preference judgments: The effects of landscape visual aesthetic quality and respondents' characteristics. J. Env. Manag. 2014, 137, 36-44. [CrossRef] [PubMed]

102. Velarde, M.D.; Fry, G.; Tveit, M. Health effects of viewing landscapes-Landscape types in environmental psychology. Urban For. Urban Green. 2007, 6, 199-212. [CrossRef]

103. Li, D.; Sullivan, W.C. Impact of views to school landscapes on recovery from stress and mental fatigue. Landsc. Urban Plan. 2016, 148, 149-158. [CrossRef]

104. Berto, R. Exposure to restorative environments helps restore attentional capacity. J. Env. Psychol. 2005, 25, 249-259. [CrossRef]

105. Jo, H.; Song, C.; Miyazaki, Y. Physiological Benefits of Viewing Nature: A Systematic Review of Indoor Experiments. Int. J. Env. Res. Public Health 2019, 16, 4739. [CrossRef]

106. Franěk, M.; Režný, L. The effect of priming with photographs of environmental settings on walking speed in an outdoor environment. Front. Psychol. 2017, 8, 73. [CrossRef]

107. Honold, J.; Lakes, T.; Beyer, R.; Van der Meer, E. Restoration in Urban Spaces: Nature Views from Home, Greenways, and Public Parks. Env. Behav. 2016, 48, 796-825. [CrossRef]

108. Ryan, R.M.; Weinstein, N.; Bernstein, J.; Brown, K.W.; Mistretta, L.; Gagné, M. Vitalizing effects of being outdoors and in nature. J. Env. Psychol. 2010, 30, 159-168. [CrossRef]

109. Buijs, A.E.; Elands, B.H.M.; Langers, F. No wilderness for immigrants: Cultural differences in images of nature and landscape preferences. Landsc. Urban Plan. 2009, 91, 113-123. [CrossRef]

110. Ho, C.-H.; Sasidharan, V.; Elmendorf, W.; Willits, F.K.; Graefe, A.; Godbey, G. Gender and Ethnic Variations in Urban Park Preferences, Visitation, and Perceived Benefits. J. Leis. Res. 2005, 37, 281-306. [CrossRef]

111. Philipp, S.F. Are We Welcome? African American Racial Acceptance in Leisure Activities and the Importance Given to Children's Leisure. J. Leis. Res. 1999, 31, 385-403. [CrossRef]

112. Galindo, M.P.G.; Rodríguez, J.A.C. Environmental Aesthetics and Psychological Wellbeing: Relationships between Preference Judgements for Urban Landscapes and Other Relevant Affective Responses. Psychol. Spain 2000, 4, $13-27$.

113. Chow, C.K.; Corsi, D.J.; Lock, K.; Madhavan, M.; Mackie, P.; Li, W.; Yi, S.; Wang, Y.; Swaminathan, S.; Lopez-Jaramillo, P.; et al. A Novel Method to Evaluate the Community Built Environment Using Photographs—Environmental Profile of a Community Health (EPOCH) Photo Neighbourhood Evaluation Tool. PLoS ONE 2014, 9, e110042. [CrossRef]

114. Anderson, L.M.; Schroeder, H.W. Application of wildland scenic assessment methods to the urban landscape. Landsc. Plan. 1983, 10, 219-237. [CrossRef]

115. Mooney, S.J.; Bader, M.D.M.; Lovasi, G.S.; Neckerman, K.M.; Teitler, J.O.; Rundle, A.G. Validity of an Ecometric Neighborhood Physical Disorder Measure Constructed by Virtual Street Audit. Am. J. Epidemiol. 2014, 180, 626-635. [CrossRef]

116. Passmore, H.-A.; Holder, M.D. Noticing nature: Individual and social benefits of a two-week intervention. J. Posit. Psychol. 2017, 12, 537-546. [CrossRef]

117. McEwan, K.; Richardson, M.; Brindley, P.; Sheffield, D.; Tait, C.; Johnson, S.; Sutch, H.; Ferguson, F.J. Shmapped: Development of an app to record and promote the well-being benefits of noticing urban nature. Transl. Behav. Med. 2020, 10, 723-733. [CrossRef]

118. Pedersen, C.H. Anchors of meaning-helpers of dialogue: The use of images in production of relations and meaning. Int. J. Qual. Stud. Educ. 2008, 21, 35-47. [CrossRef]

119. Herzog, T.R.; Colleen; Maguire, P.; Nebel, M.B. Assessing the restorative components of environments. J. Env. Psychol. 2003, 23, 159-170. [CrossRef]

120. Ewert, A.; Mitten, D.; Overholt, J. Health and Natural Landscapes: Concepts and Applications; CABI: Boston, MA, USA, $2021 ;$ p. 133.

121. Van den Berg, A.E.; Jorgensen, A.; Wilson, E.R. Evaluating restoration in urban green spaces: Does setting type make a difference? Landsc. Urban Plan. 2014, 127, 173-181. [CrossRef]

122. Wilkie, S.; Stavridou, A. Influence of environmental preference and environment type congruence on judgments of restoration potential. Urban For. Urban Green. 2013, 12, 163-170. [CrossRef]

123. Kjellgren, A.; Buhrkall, H. A comparison of the restorative effect of a natural environment with that of a simulated natural environment. J. Environ. Psychol. 2010, 30, 464-472. [CrossRef] 
124. Sherman, S.A.; Varni, J.W.; Ulrich, R.S.; Malcarne, V.L. Post-occupancy evaluation of healing gardens in a pediatric cancer center. Landsc. Urban Plan. 2005, 73, 167-183. [CrossRef]

125. Ulrich, R.S. View through a window may influence recovery from surgery. Science 1984, 224, 420-421. [CrossRef]

126. Denzin, N.K.; Lincoln, Y.S. Handbook of Qualitative Research; Sage Publications: Thousand Oaks, CA, USA, 1994.

127. Miles, M.B.; Huberman, A.M. Qualitative Data Analysis: An Expanded Sourcebook; Sage Publications: Thousand Oaks, CA, USA, 1994; p. 358.

128. Tashakkori, A.; Teddlie, C.; Teddlie, C.B. Mixed Methodology: Combining Qualitative and Quantitative Approaches; Sage Publications: Thousand Oaks, CA, USA, 24 June 1998.

129. Bryman, A. Integrating Quantitative and Qualitative Research: How Is It Done? Qual. Res. 2006, 6, 97-113. [CrossRef]

130. Maxwell, J.A. Qualitative Research Design: An Interactive Approach; Sage Publications: Thousand Oaks, CA, USA, $2012 ;$ p. 233.

131. Steinmetz-Wood, M.; Pluye, P.; Ross, N.A. The planning and reporting of mixed methods studies on the built environment and health. Prev. Med. 2019, 126, 105752. [CrossRef]

132. Creswell, J.W.; Clark, V.L.P. Designing and Conducting Mixed Methods Research; Sage Publications: Thousand Oaks, CA, USA, 2017; p. 521.

133. Zandieh, R.; Martinez, J.; Flacke, J.; Jones, P.; Van Maarseveen, M. Older Adults' Outdoor Walking: Inequalities in Neighbourhood Safety, Pedestrian Infrastructure and Aesthetics. Int. J. Env. Res. Public Health 2016, 13, 1179. [CrossRef]

134. Ramalho, J.d.A.M.; Lachal, J.; Bucher-Maluschke, J.S.N.F.; Moro, M.-R.; Revah-Levy, A. A qualitative study of the role of food in family relationships: An insight into the families of Brazilian obese adolescents using photo elicitation. Appetite 2016, 96, 539-545. [CrossRef]

135. Burton, A.; Hughes, M.; Dempsey, R.C. Quality of life research: A case for combining photo-elicitation with interpretative phenomenological analysis. Qual. Res. Psychol. 2017, 14, 375-393. [CrossRef]

136. Mmako, N.J.; Capetola, T.; Henderson-Wilson, C. Sowing social inclusion for marginalised residents of a social housing development through a community garden. Health Promot. J. Aust. 2019, 30, 350-358. [CrossRef]

137. Chawla, L. Significant Life Experiences Revisited: A Review of Research on Sources of Environmental Sensitivity. J. Env. Educ. 1998, 29, 11-21. [CrossRef]

138. Palmer, J.A. Development of Concern for the Environment and Formative Experiences of Educators. J. Env. Educ. 1993, 24, 26-30. [CrossRef]

139. Petersen, N.H.; Hungerford, R. Developmental variables affecting environmental sensitivity in professional environmental educators: A research abstract. Curr. Issues Env. Educ. Env. Stud. 1981, 7, 111-113.

140. Tanner, T. Significant Life Experiences: A New Research Area in Environmental Education. J. Env. Educ. 1980, 11, 20-24. [CrossRef]

141. Tong, A.; Sainsbury, P.; Craig, J. Consolidated criteria for reporting qualitative research (COREQ): A 32-item checklist for interviews and focus groups. Int. J. Qual. Health Care 2007, 19, 349-357. [CrossRef]

142. Tomasso, L.P.; Laurent, J.G.C.; Chen, J.T.; Catalano, P.J.; Spengler, J.D. Social and built environment antecedents to disparities in adult nature engagement. ISEE Conf. Abstr. 2021, 2021, 671.

143. NVivo Qualitative Data Analysis Software; QSR International Pty Ltd: Chadstone, Australia, Version 12; 2018.

144. MacQueen, K.M.; McLellan-Lemal, E.; Kay, K.; Milstein, B. Codebook Development for Team-Based Qualitative Analysis. CAM J. 1998, 10, 31-36. [CrossRef]

145. Krueger, R.A.; Casey, M.A. Focus Groups: A Practical Guide for Applied Research; SAGE: Los Angeles, CA, USA, 2009.

146. Seidman, I. Interviewing as Qualitative Research: A Guide for Researchers in Education and the Social Sciences; Teachers College Press: New York, NY, USA, 2006; p. 356.

147. Greene, J.; Caracelli, V.J.; Graham, W.F. Toward a Conceptual Framework for Mixed-Method Evaluation Designs. Educ. Eval. Policy Anal. 1989, 11, 255-274. [CrossRef]

148. Ulrich, R.S. Biophilia, Biophobia, and Natural Landscapes. In The Biophilia Hypothesis; Island Press: Washington, DC, USA, 1993; pp. 73-137.

149. Lumber, R.; Richardson, M.; Sheffield, D. Beyond knowing nature: Contact, emotion, compassion, meaning, and beauty are pathways to nature connection. PLOS ONE 2017, 12, e0177186. [CrossRef]

150. Gillis, K.; Gatersleben, B. A Review of Psychological Literature on the Health and Wellbeing Benefits of Biophilic Design. Buildings 2015, 5, 948-963. [CrossRef]

151. Heerwagen, J. Biophilia, health, and well-being. In Restorative Commons: Creating Health and Well-Being Through Urban Landscapes; Campbell, L., Wiesen, A., Eds.; Department of Agriculture, Forest Service, Northern Research Station: Newton Square, PA, USA, 2009; pp. 38-57.

152. Beatley, T. Biophilic Cities and Healthy Societies. Urban Plan. 2017, 2, 1-4. [CrossRef]

153. Crawford, G.; Woodworth, A.V. Biophilia and Human Health. N. Des. Ideas 2020, 4, 112-118.

154. Bolten, B.; Barbiero, G. Biophilic Design: How to enhance physical and psychological health and wellbeing in our built environments. Vis. Sustain. 2020, 13, 11-16.

155. Hartig, T.; Evans, G.W. Psychological foundations of nature experience. Adv. Psychol. 1993, 96, $427-457$.

156. Fisher, S.R. Life trajectories of youth committing to climate activism. Environ. Educ. Res. 2016, 22, 229-247. [CrossRef] 
157. Lee, K.; Gjersoe, N.; O’Neill, S.; Barnett, J. Youth perceptions of climate change: A narrative synthesis. WIREs Clim. Chang. 2020, 11, e641. [CrossRef]

158. Arnold, H.E.; Cohen, F.G.; Warner, A. Youth and Environmental Action: Perspectives of Young Environmental Leaders on Their Formative Influences. J. Env. Educ. 2009, 40, 27-36. [CrossRef]

159. Ulrich, R.S.; Simons, R.F.; Losito, B.D.; Fiorito, E.; Miles, M.A.; Zelson, M. Stress recovery during exposure to natural and urban environments. J. Env. Psychol. 1991, 11, 201-230. [CrossRef]

160. Clowney, D. Biophilia as an Environmental Virtue. J Agric Env. Ethics 2013, 26, 999-1014. [CrossRef]

161. Shaw, A.; Miller, K.; Wescott, G. Wildlife Gardening and Connectedness to Nature: Engaging the Unengaged. Env. Values 2013, 22, 483-502. [CrossRef] 